\title{
Regulation of Phenylalanine and Tyrosine Biosynthesis in Pseudomonas aureofaciens ATCC 15926
}

\author{
By ERICH BLUMENSTOCK, $\uparrow$ OLGA SALCHER \\ AND FRANZ LINGENS* \\ Institut für Mikrobiologie, \\ Universität Hohenheim, Garbenstrasse 30, D-7000 Stuttgart 70, \\ Federal Republic of Germany
}

(Received 24 May 1979; revised 25 September 1979)

\begin{abstract}
Association patterns and regulatory properties of chorismate mutase, prephenate dehydratase and prephenate dehydrogenase from Pseudomonas aureofaciens ATCC 15926 were studied. Prephenate dehydrogenase (molecular weight 95000) was separated by Sephadex G-100 chromatography from both the chorismate mutase-prephenate dehydratase I complex (molecular weight 75000) and from a second, low molecular weight prephenate dehydratase (prephenate dehydratase II ; molecular weight 30000 ). The chorismate mutaseprephenate dehydratase complex persisted after DEAE-Sephadex A-50 chromatography. With the exception of prephenate dehydratase II, enzyme activities were influenced by endproducts. Chorismate mutase was competitively inhibited by L-phenylalanine $\left(K_{\mathrm{i}}=3.5 \mu \mathrm{M}\right)$. Prephenate dehydratase I was inhibited by L-phenylalanine $\left(K_{\mathrm{i}}=8 \mu \mathrm{M}\right)$ and activated by L-tyrosine $\left(K_{\mathrm{a}}=5 \mu \mathrm{M}\right)$. Prephenate dehydrogenase was feedback-inhibited by L-tyrosine. Substrate saturation curves of chorismate mutase and of prephenate dehydratase II were hyperbolic with $K_{\mathrm{m}}$ values of $0.31 \mathrm{~mm}$ for chorismate and $0.015 \mathrm{~mm}$ for prephenate, respectively. The substrate saturation curve of the complexed prephenate dehydratase I was sigmoid; a $K_{\mathrm{m}}$ value of $0.18 \mathrm{~mm}$ was calculated for prephenate. Chorismate mutase, prephenate dehydratase and prephenate dehydrogenase were not repressed by aromatic amino acids.
\end{abstract}

\section{INTRODUCTION}

The terminal reactions in phenylalanine and tyrosine biosynthesis are accomplished by the conversion of chorismate through prephenate to phenylpyruvate or 4-hydroxyphenylpyruvate, which are then transaminated to the corresponding amino acids (Fig. 1). In micro-organisms many patterns for the regulation of these reaction sequences have evolved (Lingens, 1968). They may be used for an additional characterization of bacterial families, e.g. the Enterobacteriaceae (Cotton \& Gibson, 1970).

In Pseudomonadaceae, results from three wild-type strains of Pseudomonas aeruginosa (Ahmed \& Campbell, 1973; Calhoun et al., 1973; Stenmark-Cox \& Jensen, 1975; Waltho, 1973) and from Pseudomonas sp. ATCC 11299a (Cerutti \& Guroff, 1965) are available. Aggregation and regulation patterns of enzymes involved in phenylalanine and tyrosine biosynthesis differ amongst the $P$. aeruginosa strains ATCC 9027, PAO1 and PAT. Such a diversity is not known amongst strains of Escherichia coli. Our studies have focused on the questions of which types of regulation patterns are found in P. aureofaciens and whether they are related to the patterns observed in $P$. aeruginosa strains.

$\dagger$ Present address: Max-Planck-Institut für Immunbiologie, Stübeweg 51, D-7800 Freiburg, Federal Republic of Germany. 


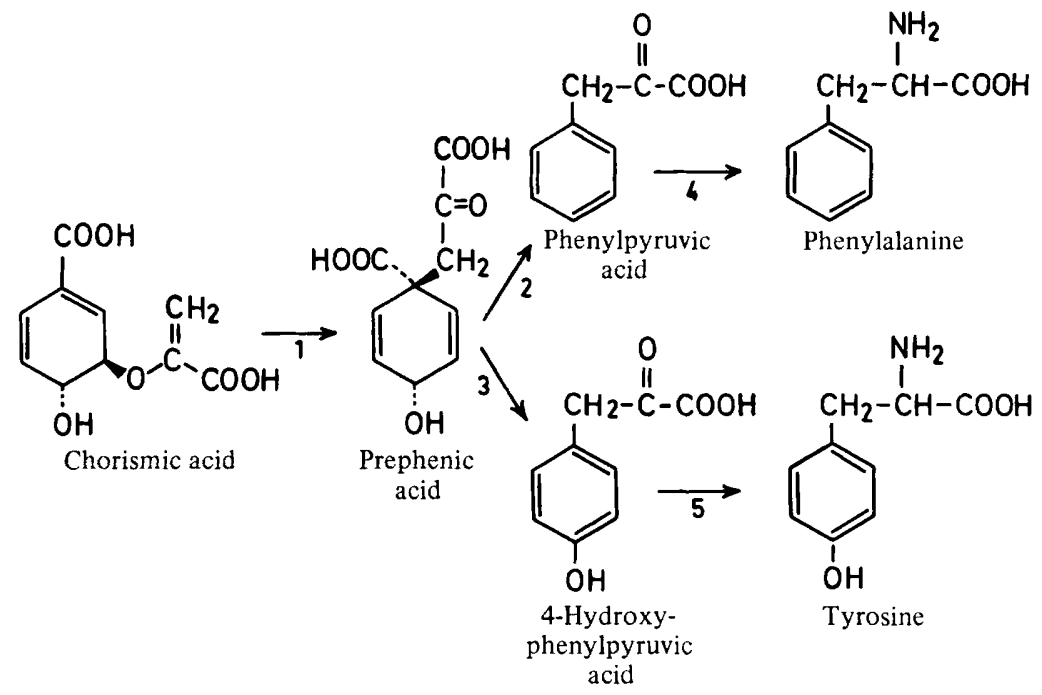

Fig. 1. Final steps in phenylalanine and tyrosine biosynthesis. Trivial names of enzymes: chorismate mutase (1), prephenate dehydratase (2), prephenate dehydrogenase (3), phenylalanine aminotransferase (4), tyrosine aminotransferase (5).

\section{METHODS}

Organism and growth conditions. Pseudomonas aureofaciens ATCC 15926 was grown at $30^{\circ} \mathrm{C}$ with vigorous aeration in a minimal medium containing $\left(\mathrm{g} \mathrm{l}^{-1}\right)$ : glycerol, $30 ; \mathrm{K}_{2} \mathrm{HPO}_{4}, 3 ; \mathrm{KH}_{2} \mathrm{PO}_{4}, 0 \cdot 5 ;\left(\mathrm{NH}_{4}\right)_{2} \mathrm{SO}_{4}, 1$; $\mathrm{NaCl}, 5 ; \mathrm{MgSO}_{4} .7 \mathrm{H}_{2} \mathrm{O}, 0.5 ; \mathrm{pH} 7 \cdot 0$. Cells for the preparation of enzymes were harvested in the lateexponential phase of growth by centrifugation. The yield was approximately $2.5 \mathrm{~g}$ wet weight cells per litre medium. The cells were stored at $-18^{\circ} \mathrm{C}$.

Enzyme assays. Buffer A (50 mM-Tris/ $\mathrm{HCl}, \mathrm{pH} 7 \cdot 7$, containing $0 \cdot 1 \mathrm{~mm}-\mathrm{EDTA})$ was used in the measurement of chorismate mutase (EC 5.4.99.5) activity by the method of Cotton \& Gibson (1965), prephenate dehydratase (EC 4.2.1.51) activity by the method of Cotton \& Gibson (1970) and prephenate dehydrogenase (EC 1.3.1.12) activity by the technique of Cotton \& Gibson (1967).

Prephenate dehydratase associated with chorismate mutase was designated prephenate dehydratase I, whereas the non-associated enzyme was termed prephenate dehydratase II.

Protein determination. Protein was determined by the biuret method (Layne, 1957) using crystalline bovine serum albumin as standard.

Extraction and purification procedures. All procedures were carried out at $4{ }^{\circ} \mathrm{C}$ using buffer $\mathrm{A}$ and buffer $\mathrm{B}(0 \cdot 15 \mathrm{M}$-Tris $/ \mathrm{HCl}$, pH $7 \cdot 7$, containing $0 \cdot 1 \mathrm{~mm}$-dithioerythritol and $0 \cdot 1 \mathrm{mM}$-EDTA). When necessary, buffers and protein solutions were supplemented with the protease inhibitor phenylmethanesulphonyl fluoride at a final concentration of $1 \mathrm{~mm}$ (Fahrney \& Gold, 1963).

Preparation of crude extracts. Frozen cells were ground with one and a half times their weight of aluminium oxide powder (Alcoa 305). The viscous paste was diluted with 4 vol. buffer A. The suspension was centrifuged at $37000 \mathrm{~g}$ for $20 \mathrm{~min}$ and the supernatant $\left(15\right.$ to $20 \mathrm{mg}$ protein $\mathrm{ml}^{-1}$ ) was used in further studies.

Ammonium sulphate fractionation. Powdered $\left(\mathrm{NH}_{4}\right)_{2} \mathrm{SO}_{4}$ (enzyme grade) was slowly added to the crude extract $\left(15 \mathrm{mg}\right.$ protein $\left.\mathrm{ml}^{-1}\right)$. After stirring for $20 \mathrm{~min}$, the precipitate was collected by centrifugation $(20000 \mathrm{~g}, 20 \mathrm{~min})$ and dissolved in buffer $\mathrm{A}$. The resulting protein solution $\left(35 \mathrm{mg} \mathrm{ml}^{-1}\right)$ was dialysed for $2 \mathrm{~h}$ against 1000 vol. buffer $\mathrm{A}$ and stored at $-18^{\circ} \mathrm{C}$, if not used immediately.

Sephadex G-100 chromatography. Dialysed protein solution $(1 \mathrm{ml}$, containing 25 to $35 \mathrm{mg}$ protein) obtained by $\left(\mathrm{NH}_{4}\right)_{2} \mathrm{SO}_{4}$ fractionation $(0$ to $80 \%$ saturation) was layered directly on to the gel surface of a Sephadex G-100 column $(2.5 \times 80 \mathrm{~cm})$ previously equilibrated with buffer A. A flow rate of $17 \mathrm{ml} \mathrm{h}^{-1} \mathrm{of}^{-}$ buffer A was maintained and $2.5 \mathrm{ml}$ fractions were collected. Active fractions that had to be rechromatographed were pooled and concentrated by addition of $\left(\mathrm{NH}_{4}\right)_{2} \mathrm{SO}_{4}$ up to $90 \%$ saturation before being applied to a Sephadex G-100 or a DEAE-Sephadex column.

DEAE-Sephadex chromatography. An $\left(\mathrm{NH}_{4}\right)_{2} \mathrm{SO}_{4}$ fraction (0 to $80 \%$ saturation) was prepared as described above, but using buffer $B$. The resulting protein solution $\left(35 \mathrm{mg} \mathrm{ml}^{-1}\right)$ was dialysed against 500 vol. buffer $B$ with two equal changes during $8 \mathrm{~h}$. Dialysed protein solution $(1 \mathrm{ml}$, containing $20 \mathrm{mg}$ 


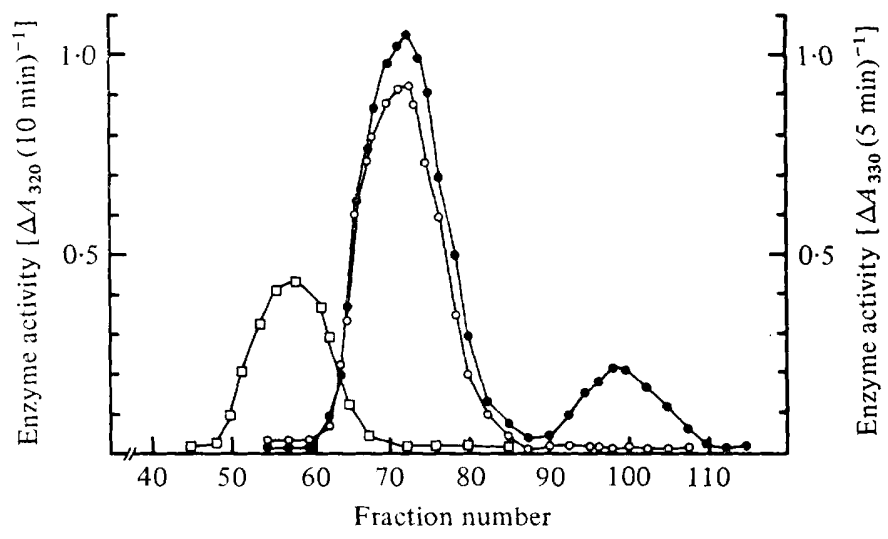

Fig. 2. Sephadex G-100 chromatography of a 0 to $80 \%$ saturated $\left(\mathrm{NH}_{4}\right)_{2} \mathrm{SO}_{4}$ fraction of crude extract from $P$. aureofaciens. Activities of chorismate mutase $(\bigcirc)$, prephenate dehydratase $(\odot)$ and prephenate dehydrogenase $(\square)$ were measured in all fractions (see Methods). All procedures were carried out in presence of $1 \mathrm{~mm}$-phenylmethanesulphonyl fluoride.

protein) was applied to a DEAE-Sephadex A-50 column $(1.6 \times 25 \mathrm{~cm})$ previously equilibrated with buffer B. After the column had been washed with buffer B, enzymes were eluted by a linear gradient of 0 to $0.4 \mathrm{M}-\mathrm{NaCl}$ in buffer B. Fractions of $2.5 \mathrm{ml}$ were collected at a flow rate of $15 \mathrm{ml} \mathrm{h}^{-1}$.

Estimation of molecular weights. The molecular weights of chorismate mutase, prephenate dehydratase and prephenate dehydrogenase were estimated by gel filtration (Andrews, 1964). Approximately $20 \mathrm{mg}$ protein from a 0 to $80 \%$ saturated $\left(\mathrm{NH}_{4}\right)_{2} \mathrm{SO}_{4}$ fraction of crude extract in $1 \mathrm{ml}$ buffer A were applied to a Sephadex G-100 column $(2.5 \times 80 \mathrm{~cm})$. The column was calibrated using the following marker proteins of known molecular weight: bovine serum albumin (dimer form, 134000; monomer form, 67000), bovine chymotrypsinogen A (25000), and cytochrome $c$ from horse heart (12400). Proteins were eluted with buffer $\mathrm{A}$ at a flow rate of $17 \mathrm{ml} \mathrm{h}^{-1}$ and $2.5 \mathrm{ml}$ fractions were collected. The void volume was determined with blue dextran.

Chemicals and biochemicals. All reagents used were of the highest purity grade available. Chorismate (Gibson, 1970) and prephenate (Dayan \& Sprinson, 1970) were prepared by standard methods.

\section{RESULTS AND DISCUSSION}

\section{Ammonium sulphate fractionation}

The distribution of chorismate mutase and prephenate dehydratase activities was determined in protein fractions obtained by precipitation with increasing concentrations of $\left(\mathrm{NH}_{4}\right)_{2} \mathrm{SO}_{4}$ (0 to 30,30 to 40,40 to 50,50 to 70 and 70 to $90 \%$ saturation). Chorismate mutase activity was present in the first three fractions, whereas prephenate dehydratase was distributed throughout the fractions. In the course of feedback inhibition experiments it was found that prephenate dehydratase (prephenate dehydratase I) in $\left(\mathrm{NH}_{4}\right)_{2} \mathrm{SO}_{4}$ fractions up to $50 \%$ saturation was inhibited by $0.1 \mathrm{~mm}-\mathrm{L}$-phenylalanine and activated by $0.1 \mathrm{mM}-\mathrm{L}-$ tyrosine, whereas prephenate dehydratase activities from $\left(\mathrm{NH}_{4}\right)_{2} \mathrm{SO}_{4}$ fractions of higher saturations ( 50 to $90 \%$ ) were not influenced by either amino acid (prephenate dehydratase II). The possible existence of two differently regulated prephenate dehydratase activities was therefore studied in detail by gel filtration.

\section{Sephadex G-100 chromatography}

The elution profile (Fig. 2) of an $\left(\mathrm{NH}_{4}\right)_{2} \mathrm{SO}_{4}$ fraction ( 0 to $80 \%$ saturation) on Sephadex G-100 showed a single peak of prephenate dehydrogenase activity followed by a peak containing chorismate mutase as well as prephenate dehydratase activity. An additional peak exhibiting prephenate dehydratase activity was eluted separately. The recovery of 


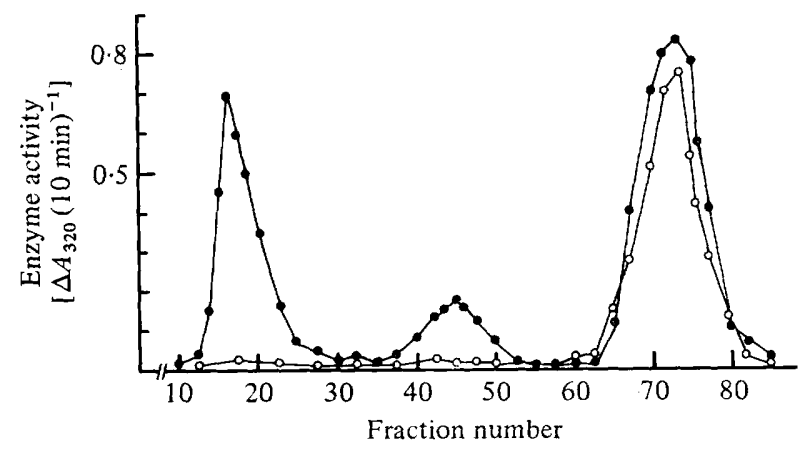

Fig. 3. DEAE-Sephadex chromatography of a 0 to $80 \%$ saturated $\left(\mathrm{NH}_{4}\right)_{2} \mathrm{SO}_{4}$ fraction of crude extract from $P$. aureofaciens. Activities of chorismate mutase $(O)$ and prephenate dehydratase $(\bullet)$ were assayed as described in Methods. All procedures were carried out in presence of $1 \mathrm{~mm}$-phenylmethanesulphonyl fluoride.

chorismate mutase-prephenate dehydratase I and prephenate dehydratase II activity was usually $80 \%$, while that of prephenate dehydrogenase was $60 \%$. The regulatory properties of these enzyme activities in the eluates were identical to those of the enzyme activities from $\left(\mathrm{NH}_{4}\right)_{2} \mathrm{SO}_{4}$ fractions. Prephenate dehydrogenase was inhibited by $0.1 \mathrm{mM}$-L-tyrosine.

Similar results were obtained when crude extracts were directly applied to the Sephadex G-100 column. This indicates that splitting of prephenate dehydratase activity was not caused by $\left(\mathrm{NH}_{4}\right)_{2} \mathrm{SO}_{4}$ fractionation. The preparation of enzyme extracts and the Sephadex G-100 chromatography were also done in the presence of 1 mM-phenylmethanesulphonyl fluoride. The sequence of elution as well as the regulatory properties of the enzymes were not altered, but the elution profile showed a more regular shape due to inhibition of proteolytic activities.

\section{$D E A E$-Sephadex chromatography}

The elution patterns of chorismate mutase and prephenate dehydratase activities were also studied by ion-exchange chromatography (Fig. 3). The phenylalanine-insensitive prephenate dehydratase II was eluted from the DEAE-Sephadex column in two successive peaks (recovery of enzyme activity $75 \%$ ) followed by the phenylalanine-sensitive prephenate dehydratase I, which co-eluted with chorismate mutase (recovery of enzyme activity $62 \%$ ).

Rechromatographed fractions of prephenate dehydratase II (recovery of enzyme activity $90 \%$ ) from Sephadex G-100 or A-50 columns eluted as single peaks whose position corresponded to the first chromatographic profiles. Fractions of the chorismate mutaseprephenate dehydratase I aggregate (recovery of enzyme activity $85 \%$ ) again showed two small successive peaks of prephenate dehydratase II activity upon rechromatography. The same results were obtained in the presence of phenylmethanesulphonyl fluoride. A working hypothesis might therefore be that prephenate dehydratase II is a dissociation product of prephenate dehydratase I. In Pseudomonas sp. ATCC 11299a (Cerutti \& Guroff, 1965) and in $P$. aeruginosa strain PAT (Waltho, 1973) only one enzyme activity of chorismate mutase or prephenate dehydratase was detected. For $P$. aeruginosa strain PAO1 an enzyme complex of chorismate mutase and prephenate dehydratase was reported, as well as a second chorismate mutase and prephenate dehydratase, which were not aggregated (Calhoun et al., 1973; Patel et al., 1977). Two enzyme complexes each containing chorismate mutase and prephenate dehydratase activity were found in $P$. aeruginosa ATCC 9027 (Ahmed \& Campbell, 1973). Data from column chromatography of prephenate dehydrogenase are available for $P$. aeruginosa strain PAO1 and $P$. aeruginosa ATCC 9027. No aggregation with other enzymes of the pathway (Ahmed \& Campbell, 1973; Stenmark-Cox \& Jensen, 1975) was observed. For Pseudomonas sp. ATCC 11299a a biosynthetic role of 
Table 1. Effect of aromatic amino acids on chorismate mutase, prephenate dehydratase I and II and prephenate dehydrogenase activity from $P$. aureofaciens

\begin{abstract}
For assaying chorismate mutase and prephenate dehydratase I a 0 to $40 \%$ saturated $\left(\mathrm{NH}_{4}\right)_{2} \mathrm{SO}_{4}$ fraction of crude extract was used and for prephenate dehydratase II a 60 to $90 \%$ saturated $\left(\mathrm{NH}_{4}\right)_{2} \mathrm{SO}_{4}$ fraction of crude extract was used. The prephenate dehydrogenase assay contained protein from crude extract. Enzyme activities were assayed as described in Methods and are expressed relative to the activities without added amino acids. The specific activities in the control assays were $\left[\mathrm{nmol} \mathrm{min}^{-1}(\mathrm{mg} \text { protein })^{-1}\right]$ : chorismate mutase, 78 ; prephenate dehydratase $\mathrm{I}, 71$; prephenate dehydratase II, 23; prephenate dehydrogenase, 12.
\end{abstract}

Relative enzyme activity

$\begin{array}{lcccc}\begin{array}{l}\text { L-Amino acid(s) added } \\ (0.1 \mathrm{mM})\end{array} & \begin{array}{c}\text { Chorismate } \\ \text { mutase }\end{array} & \begin{array}{c}\text { Prephenate } \\ \text { dehydratase I }\end{array} & \begin{array}{c}\text { Prephenate } \\ \text { dehydratase II }\end{array} & \begin{array}{c}\text { Prephenate } \\ \text { dehydrogenase }\end{array} \\ \text { None } & 1.00 & 1.00 & 1.00 & 1.00 \\ \text { Phenylalanine } & 0.66 & 0.38 & 0.97 & 1.00 \\ \text { Tryptophan } & 0.93 & 1.02 & 1.00 & 1.01 \\ \text { Tyrosine } & 0.93 & 1.5 & 1.00 & 0.51 \\ \text { Phenylalanine + tyrosine } & 0.68 & 0.41 & 1.02 & 0.5 \\ \text { Phenylalanine + tryptophan } & 0.68 & 0.38 & 1.00 & 1.00 \\ \text { Tryptophan +tyrosine } & 0.99 & 1.45 & 1.00 & 0.5 \\ \text { Phenylalanine+tryptophan } & 0.68 & 0.4 & 0.98 & 0.54\end{array}$

phenylalanine hydroxylase was discussed. However, this inducible catabolic enzyme was not detected in $P$. aureofaciens ATCC 15926 (O. Salcher \& F. Lingens, unpublished results).

\title{
Molecular weight estimation
}

Molecular weights were estimated by gel filtration with Sephadex G-100. Prephenate dehydrogenase was eluted at a position corresponding to a molecular weight of 95000 . The chorismate mutase-prephenate dehydratase I aggregate and prephenate dehydratase II had molecular weights of 75000 and 30000 , respectively.

For $P$. aeruginosa strain PAOl, the molecular weights of the corresponding enzymes determined by the same method were: prephenate dehydrogenase, 150000 ; the chorismate mutase-prephenate dehydratase I aggregate, 134000; the second prephenate dehydratase, 76000 (Calhoun et al., 1973); the second chorismate mutase, 27000 (Patel et al., 1977).

\section{Regulation of enzyme activity by aromatic amino acids}

The influence of aromatic amino acids on enzyme activities was studied using protein from $\left(\mathrm{NH}_{4}\right)_{2} \mathrm{SO}_{4}$ fractions (Tables 1 and 2). Similar results to those described below were obtained with fractions purified by gel filtration and ion-exchange chromatography. Chorismate mutase activity was feedback-inhibited by $0.1 \mathrm{mM}-\mathrm{L}-$ phenylalanine, but the enzyme activity was not influenced by $0.1 \mathrm{~mm}$-L-tyrosine. L-Tryptophan exerted no regulatory control on the enzymes of phenylalanine or tyrosine synthesis. D-Tyrosine was almost as efficient ( $30 \%$ activation) as L-tyrosine in activating prephenate dehydratase I. Other aromatic D-amino acids were inactive. Inhibition of prephenate dehydratase I by $10 \mu \mathrm{M}$-L-phenylalanine was reversed by $50 \mu \mathrm{M}$-L-tyrosine. Prephenate dehydratase II was not inhibited by aromatic amino acids, even when low concentrations of prephenate $(0.012$ to $0.04 \mathrm{~mm})$ were used as substrate. Kinetic studies revealed further distinguishing features of the two prephenate dehydratase activities. The $K_{\mathrm{m}}$ value for prephenate of prephenate dehydratase II was about tenfold lower than that of prephenate dehydratase I (Table 2).

Plots of prephenate dehydratase I activity against various prephenate concentrations were sigmoid. Sigmoidicity was intensified by the inhibitor L-phenylalanine. The activator 
Table 2. Comparison of kinetic properties of the chorismate mutase-prephenate dehydratase I aggregate and the prephenate dehydratase II from $P$. aureofaciens

Assays for chorismate mutase and prephenate dehydratase I contained protein from a 0 to $30 \%$ saturated $\left(\mathrm{NH}_{4}\right)_{2} \mathrm{SO}_{4}$ fraction of crude extract. Assays for prephenate dehydratase II were performed with a 60 to $90 \%$ saturated $\left(\mathrm{NH}_{4}\right)_{2} \mathrm{SO}_{4}$ fraction of crude extract. Enzyme activities were assayed as described in Methods. The $K_{\mathrm{i}}$ value of L-phenylalanine in the chorismate mutase reaction was determined at $0.9 \mathrm{~mm}$-chorismate. The $K_{\mathrm{i}}$ value of $\mathrm{L}$-phenylalanine in the prephenate dehydratase I reaction as well as the $K_{\mathrm{a}}$ value of L-tyrosine were each determined at $0.34 \mathrm{~mm}$ prephenate. Values of $K_{\mathrm{m}}, K_{\mathrm{i}}$ and $K_{\mathrm{a}}$ were generally determined from Lineweaver-Burk plots except those for prephenate dehydratase I which were calculated from curves by the method of Koshland et al. (1966).

\begin{tabular}{|c|c|c|c|c|c|c|}
\hline Enzyme & $\begin{array}{c}K_{\mathrm{m}} \\
\text { value } \\
(\mathrm{mm})\end{array}$ & $\begin{array}{l}\text { Substrate } \\
\text { saturation } \\
\text { curve }\end{array}$ & Inhibitor & $\begin{array}{c}K_{\mathrm{i}} \\
\text { value } \\
(\mu \mathrm{M})\end{array}$ & Activator & $\begin{array}{r}K_{\mathrm{a}} \\
\text { valuc } \\
(\mu \mathrm{M})\end{array}$ \\
\hline $\begin{array}{l}\text { Chorismate } \\
\text { mutase }\end{array}$ & $0 \cdot 31$ & Hyperbolic & L-Phenylalanine & $3 \cdot 5$ & None & 0 \\
\hline $\begin{array}{l}\text { Prephenate } \\
\text { dehydratase I }\end{array}$ & $0 \cdot 18$ & Sigmoid & L-Phenylalanine & 8 & L-Tyrosine & 5 \\
\hline $\begin{array}{l}\text { Prephenate } \\
\text { dehydratase II }\end{array}$ & 0.015 & Hyperbolic & None & 0 & None & 0 \\
\hline
\end{tabular}

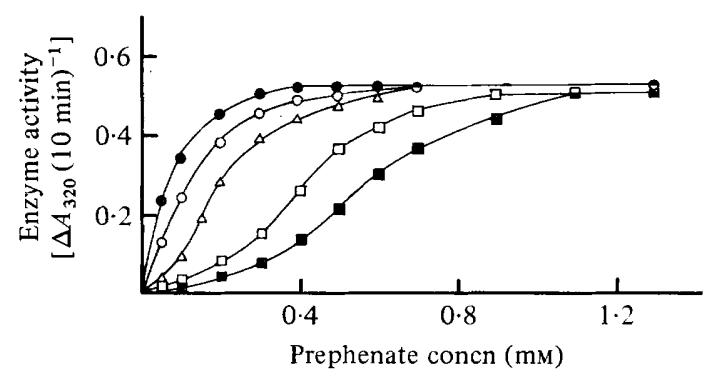

Fig. 4. Effects of L-phenylalanine and L-tyrosine on the substrate saturation curve of prephenate dehydratase I from $P$. aureofaciens. The assay for prephenate dehydratase I was done with protein $(55 \mu \mathrm{g})$ from a 0 to $40 \%$ saturated $\left(\mathrm{NH}_{4}\right)_{2} \mathrm{SO}_{4}$ fraction of crude extract as described in Methods. Assays contained $4 \mu \mathrm{M}(\bigcirc)$ or $40 \mu \mathrm{M}(\bigcirc)$ L-tyrosine, $8 \mu \mathrm{M}(\square)$ or $14 \mu \mathrm{M}(\square)$ L-phenylalanine, or no added amino acids $(\triangle)$.

L-tyrosine converted the substrate saturation curve to a simple Michaelis-Menten hyperbola (Fig. 4).

In $P$. aeruginosa $\mathrm{PAO} 1$ the bifunctional enzyme chorismate mutase-prephenate dehydratase was inhibited by L-phenylalanine (Patel et al., 1977). However, inhibition of chorismate mutase was lost during purification by either gel filtration or ion-exchange chromatography (Calhoun et al., 1973). Chorismate mutase from strain PAT was also inhibited by L-tyrosine (Waltho, 1973). In crude extracts of strain ATCC 9027 both chorismate mutase-prephenate dehydratase aggregates were insensitive to aromatic amino acids. After purification by ion-exchange chromatography, the so-called second prephenate dehydratase activity had become sensitive to inhibition by L-phenylalanine, and the inhibition was reversed by L-tyrosine (Ahmed \& Campbell, 1973). The latter effect was also reported for the other $P$. aeruginosa strains studied and for Pseudomonas sp. ATCC 11299a (Cerutti \& Guroff, 1965). The non-complexed chorismate mutase and the prephenate dehydratase from $P$. aeruginosa strain PAOl were not influenced by either amino acid (Calhoun et al., 1973; Patel et al., 1977). This was also observed for chorismate mutase from Pseudomonas sp. ATCC 11299a (Cerutti \& Guroff, 1965). With the exception of Pseudomonas sp. ATCC 11299a (Cerutti \& Guroff, 1965), prephenate dehydrogenases of the above-mentioned $P$. aeruginosa strains were inhibited by L-tyrosine. So far the two 
forms of prephenate dehydratase found in strains of $P$. aeruginosa have not been compared in kinetic studies. In our study the enzymes of phenylalanine and tyrosine biosynthesis were not repressed by aromatic amino acids $(3 \mathrm{~mm})$, which were also used as sole sources of carbon by $P$. aureofaciens. Extracts prepared from bacteria grown under conditions of potential repression were also tested for effects of L-phenylalanine and L-tyrosine on enzyme activities. No differences in the pattern of inhibition or activation were apparent, suggesting the absence of isoenzymes altered in regulatory properties. These results are consistent with those described for other pseudomonads.

We thank the Fonds der Chemischen Industrie for support and Mrs M. Vann for reading the manuscript.

\section{REFERENCES}

Ahmed, S. I. \& Campbell, J. J. R. (1973). A bifunctional enzyme in Pseudomonas aeruginosa: a new pattern in the organization of enzymes concerned with phenylalanine and tyrosine biosynthesis. Journal of Bacteriology 115, 205-212.

ANDREWS, P. (1964). Estimation of the molecular weights of proteins by Sephadex gel-filtration. Biochemical Journal 91, 222-233.

Calhoun, D. H., Pierson, D. L. \& Jensen, R. A. (1973). Channel-shuttle mechanism for the regulation of phenylalanine and tyrosine synthesis at a metabolic branch point in Pseudomonas aeruginosa. Journal of Bacteriology 113, 241-251.

Cerutti, P. \& Guroff, G. (1965). Enzymatic formation of phenylpyruvic acid in Pseudomonas sp. (ATCC 11299a) and its regulation. Journal of Biological Chemistry 240, 3034-3038.

Cotton, R. G. H. \& Gibson, F. (1965). The biosynthesis of phenylalanine and tyrosine: enzymes converting chorismic acid into prephenic acid and their relationships to prephenate dehydratase and prephenate dehydrogenase. Biochimica et biophysica acta 100, 76-88.

Cotton, R. C. H. \& Gibson, F. (1967). The biosynthesis of tyrosine in Aerobacter aerogenes: partial purification of the $\mathrm{T}$ protein. Biochimica et biophysica acta 147, 222-237.

Cotton, R. G. H. \& Gibson, F. (1970). Tyrosine and phenylalanine biosynthesis: the $\mathrm{T}$ and $\mathrm{P}$ proteins (Aerobacter aerogenes), chorismate mutase (Pisum sativum). Methods in Enzymology 17A, 564-574.

Dayan, J. \& Sprinson, D. B. (1970). Preparation of prephenic acid. Methods in Enzymology 17A, 559-561.

Fahrney, D. E. \& Gold, A. M. (1963). Sulfonyl fluorides as inhibitors of esterases. 1. Rates of reaction with acetylcholinesterase, $\alpha$-chymotrypsin and trypsin. Journal of the American Chemical Society 85, 997-1000.

Gibson, F. (1970). Preparation of chorismic acid. Methods in Enzymology 17A, 362-364.

Koshland, D. E., JR, Némethy, G. \& Filmer, D. (1966). Comparison of experimental binding data and theoretical models in proteins containing subunits. Biochemistry 5, 365-385.

LAYNE, F. (1957). Spectrometric and turbidimetric methods for measuring proteins. Methods in Enzymology 3, 447-454.

LINGENS, F. (1968). The biosynthesis of aromatic amino acids and its regulation. Angewandte Chemie (International Edition in English) 7, 350 360.

Patel, N., Pierson, D. L. \& Jensen, R. A. (1977). Dual enzymatic routes to L-tyrosine and L-phenylalanine via pretyrosine in Pseudomonas aeruginosa. Journal of Biological Chemistry 252, 5839-5846.

Stenmark-Cox, S. \& Jensen, R. A. (1975). Prephenate dehydrogenase from Pseudomonas aeruginosa is a regulated component of the channelshuttle mechanism controlling tyrosine-phenylalanine synthesis. Archives of Biochemistry and Biophysics 167, 540-546.

WaLtho, J. A. (1973). Regulation of phenylalanine biosynthesis in Pseudomonas aeruginosa. Biochimica et biophysica acta 320, 232-241. 